\title{
A prospective nonrandomized clinical study on exudative age related macular degeneration
}

\begin{abstract}
Introduction: Age-related macular degeneration (ARMD) is the leading cause of irreversible blindness in individuals over 50 years in developed countries. The objective was to study the various fundus fluorescein angiogram (FFA) patterns of exudative ARMD and monitor the treatment response and the change in visual acuity, macular thickness, angiographic patterns following intravitreal injection of bevacizumab and to assess the systemic risk factors for exudative ARMD. Materials and Methods: This prospective nonrandomized clinical study was carried out among 50 patients of ARMD diagnosed by FFA and optical coherence tomogram (OCT) with best corrected visual acuity of $<6 / 24$ (Snellen's chart), Macular thickness by OCT, FFA was done before and after giving injection of bevacizumab. Patients were asked for regular followup at 2 weeks, 4 weeks, 8 weeks, 12 weeks and 16 weeks. Results: Fifty-two percent cases with classic choroidal neovascular membrane (CNVM) showed 1 line improvement at the end of 2 months and $56 \%$ of cases showing 2 lines improvement at 4 months. About $50 \%$ of occult CNVM showed more than 2 lines improvement at 4 months. About $50 \%$ of Classic CNVM and $40 \%$ of occult CNVM showed reduction in macular thickness of $50 \mu$ at the end of 2 months, and $52 \%$ of both CNVM types showed reduction of $100 \mu$ at the end of 4 months. Conclusions: In India ophthalmologists feel that AMD is an uncommon condition. By this study, we proved that although its prevalence rate is low in India as compared with Western countries, Indians are not immune from developing AMD.
\end{abstract}

Key words: Bevacizumab, fundus fluorescein angiogram, optical coherence tomogram
Ayakutty Muni Raja, Siddharam Janti, Charanya Chendilnathan, Adnan Matheen

Department of Ophthalmology, Chettinad Hospital and Research Institute, Kelambakkam, Chennai, Tamil Nadu, India

Address for the Correspondence: Dr. C. Charanya, A 401, Urbanville Velachery Main Road, Velachery, Chennai - 600042 , Tamil Nadu, Chennai, India. E-mail: charanyachendilnathan@ gmail.com

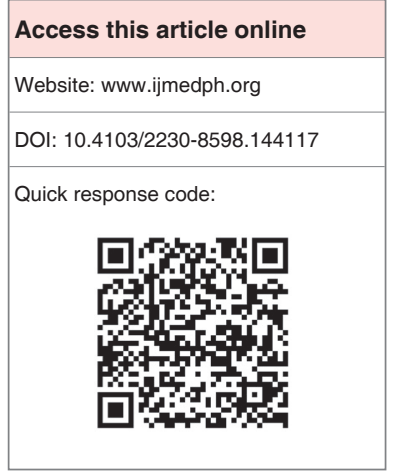

\section{INTRODUCTION}

Age related macular degeneration (ARMD) was responsible for $8.7 \%$ of all cases of blindness worldwide in 2007, and this figure is expected to double by 2020 as a result of population ageing. ${ }^{[1]}$ Senile macular degeneration was first reported as a clinical entity in 1885 by Otto Haab. He described a variety of pigmentary and atrophic changes in the macular region causing progressive impairment of central vision in patients more than 50 years. ${ }^{[2]}$ In the Framingham Eye study, an eye was considered to have ARMD if pigment changes, drusen, retinal changes associated with choroidal neovascularization [Figure 1] in individuals over 50 years of age were thought to be responsible for visual loss to 20/30 or worse, not as a result of cataract or other eye disease. ${ }^{[3]}$ The National Eye Institute estimated that there may be more than 16,000 new cases of legal blindness yearly from this disease. ${ }^{[4]}$ The risk of developing AMD is in excess of $35 \%$ by the age of 75 , and is increased by a family history of the disease or environmental factors such as cigarette smoking, nutritional deficiency, excessive sunlight exposure and hypertension. It could also present as the late-onset of genetic disease, but age is the most significant of all risk factors. ${ }^{[5]}$ Women have higher prevalence rates than men. ${ }^{[6]}$ The retinal pigment epithelium (RPE), Bruch's membrane and the choriocapillaries must function efficiently to serve as the nutritional complex for the photoreceptors. In a normal eye, there are no deposits beneath the RPE. ${ }^{[7]}$ The choroidal neovascular membrane (CNVM) that originate from the choriocapillaries grow under the RPE and retina through break in Bruch's membrane. The new vessels can be stimulated by vascular endothelial growth factor (VEGF) and tissue growth factors ${ }^{[8]}$ Studies have demonstrated that $54 \%$ of visible vessels grow toward the fovea at the rate of 10-18 microns daily in a 3 weeks period. ARMD can be nonexudative or exudative types [Figure 2]. Nonexudative or dry ARMD was most common type (90\%) of macular degeneration which was characterized by RPE changes and drusen (yellowish deposition between RPE and Bruchs membrane) and geographical atrophy. ${ }^{[9]}$ Exudative ARMD (10\%) or wet 
ARMD characterized by CNVM, pigment epithelial detachment (PED), disciform scar. ${ }^{[10]}$ Based on fundus fluorescein angiogram (FFA), CNVM can be divided into classic CNVM (well defined early hyperfluorescence with late leakage) and occult CNVM (fibrovascular PED and late leakage from undetermined source) [Figure 3]. ${ }^{[1]}$ Exudative macular degeneration effectively managed with antiVEGF factors like - pegaptanib (Macugen), bevacizumab (Avastin), ranibizumab (Lucentis). Laser photocoagulation, photodynamic therapy (Verteporfin), pupillary thermotherapy are other options for managing macular degeneration. ${ }^{[12]}$ Current NICE guidelines recommend ranibizumab as treatment for wet AMD if the patient has all of the following criteria: The best possible visual acuity after correction with glasses or contact lenses is between $6 / 12$ and 6/96. There is no permanent damage to the fovea. The area affected by AMD is no larger than 12 times the size of the optic disc. ${ }^{[13]}$ Although ranibizumab and pegaptanib are the only two drugs with licensing approval, bevacizumab, a recombinant humanized monoclonal antibody against all VEGF-A isoforms, has shown considerable promise as an off label treatment method. Trials have shown that bevacizumab can penetrate through all layers of the retina, and it has been used off license as AMD treatment to positive effect with recordings showing reduced retinal thickening and improved visual acuity. ${ }^{[14]}$ We wanted to study the various FFA patterns of exudative ARMD and monitor the treatment response and the change in visual acuity, macular thickness, angiographic patterns following intravitreal injection of bevacizumab and to assess the systemic risk factors for exudative ARMD in South Indian population because majority of the studies have been done in US and Europe. There were limited studies about ARMD in developing countries like India.

\section{MATERIALS AND METHODS}

After Institutional Ethical Committee clearance, this prospective nonrandomized study was done in Retina Clinic of Regional Institute Ophthalmology Madras Medical College, Chennai during the period of June 2007 to November 2009. About 50 patients selected by random sampling technique who had CNVM attributable to ARMD diagnosed by FFA and optical coherence tomogram (OCT) with best corrected visual acuity (BCVA) of $<6 / 24$ were included in the study after obtaining an informed written consent. Patients with nonexudative ARMD, high myopia, chronic uveitis, diabetic retinopathy, hypertensive retinopathy and mature cataract were excluded from the study. Vision in both eyes was tested using Snellen's visual acuity chart. Other materials used were intraocular pressure measurement by Goldmann applanation tonometer, anterior segment examination with slit lamp biometry, fundus examination — pupil was dilated with $1 \%$ tropicamide dilating eye drops, fundus examination was done with a direct ophthalmoscope, indirect ophthalmoscope, slit lamp with +90D lens and Goldmann 3 mirror. Fundus photograph was taken with Topcon fundus camera. FFA was done with $3 \mathrm{ml}$ of $20 \%$ sodium flourescein injection intravenous in dorsal vein of the hand with patient seated in front of the fundus camera. OCT was done [Figure 4]. A commercially available bevacizumab $(1.25 \mathrm{mg} / 0.05 \mathrm{ml})$ was prepared for each patient and placed in a tuberculin syringe using aseptic techniques. After

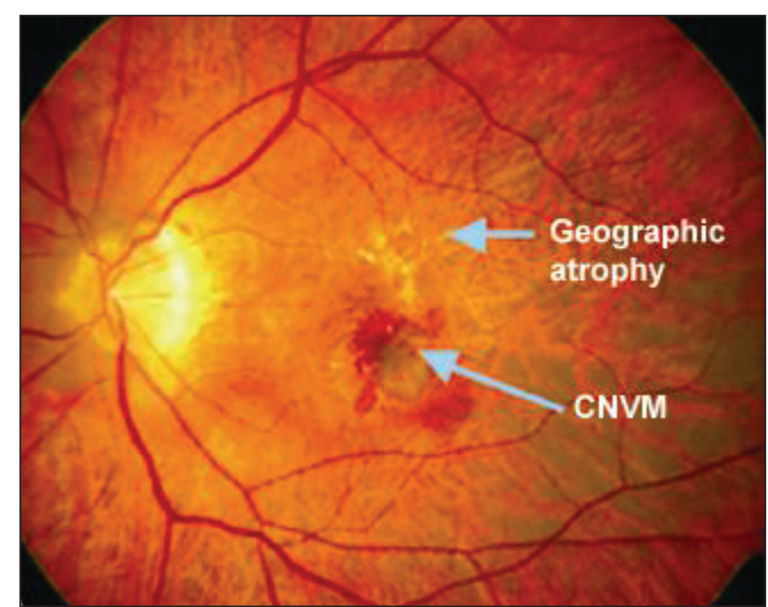

Figure 1: Fundus shows Geographic atrophy and choroidal neovascular membrane in the macula

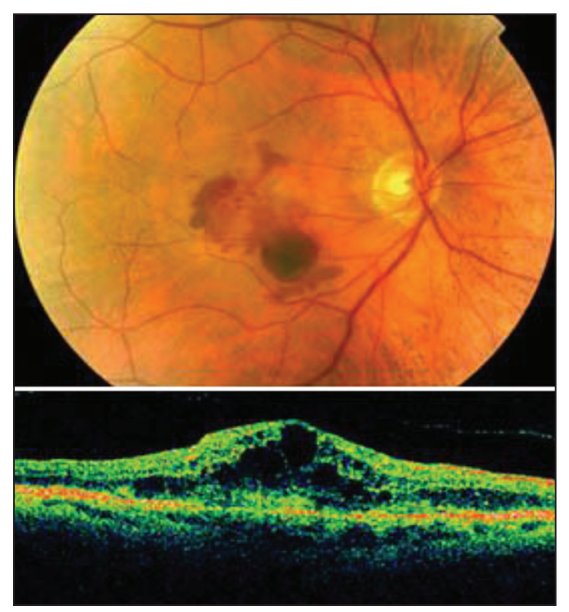

Figure 2: Exudative age related macular degeneration in the macula with corresponding increased macular thickness $(450 \mu)$ in optical coherence tomogram

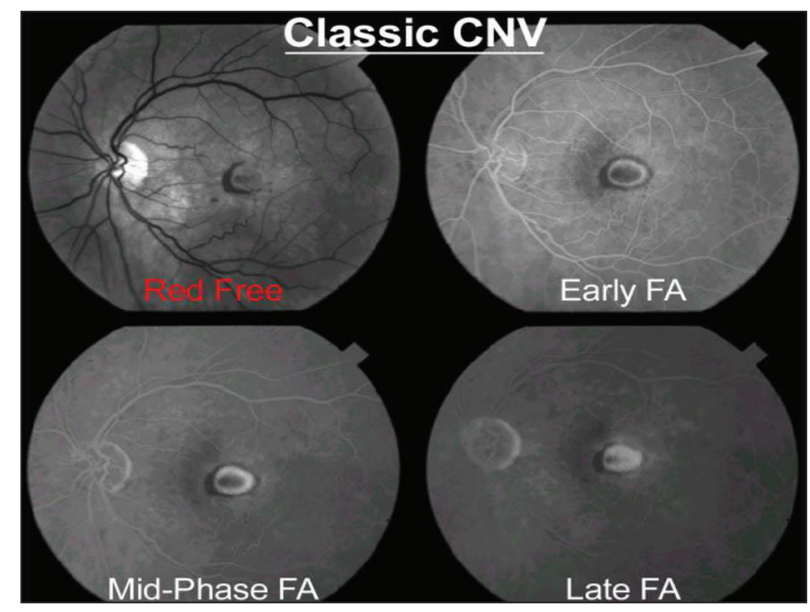

Figure 3: In fundus fluorescein angiogram classic choroidal neovascular membrane shows lacy pattern of hyperfluorescence in early phase and increase intensity in mid phase and leaks in the late phase obscuring the boundaries 
the eye had been prepared in a standard fashion using $5 \%$ povidone iodine and topical antibiotics, $1.25 \mathrm{mg}(0.05 \mathrm{ml})$ of bevacizumab was injected intravitreally via the parsplana. After the injection, intraocular pressure and retinal artery perfusion were checked, and patients were instructed to administer topical antibiotics for 3 days. Patients were called 2-3 days after injection and were re-examined within 1 week. All the patients were asked for regular follow-up at 2 weeks, 4 weeks, 8 weeks, 12 weeks and 16 weeks. At each visit patients were checked for intraocular pressure, BCVA (Snellen's chart), macular thickness by OCT (SPECTRAL). Changes in fluorescein angiogram patterns in the form of reduction in size of the lesion and decrease in leakage were considered. The results were analyzed using SPSS software.

\section{RESULTS}

A total of 50 patients were studied during June 2007 to November 2009. Among them, $74 \%$ were above the age of 60 years, and the remaining $26 \%$ were below 60 years. The ratio of male to female in our study was $2.3: 1$. About $94 \%$ of the patients had bilateral involvement although both eyes were affected asymmetrically. More than $60 \%$ of the patients were chronic smokers; $66 \%$ had hypertension. Forty-four percent had nonspecific cardiac ailments, and $10 \%$ had diabetes [Table 1]. Most of the patients reported late to the hospital- $44 \%$ of the patients reported between 4 and 6 months and $32 \%$ between 7 and 12 months. About $30 \%$ of the patients presented to us very late in the course of the disease, when the vision was $<1 / 60 ; 40 \%$ had the vision between $2 / 60$ and $4 / 60$ and rest $30 \%$ had vision between 5/60 and 6/24. FFA showed $68 \%$ of patients were with classical angiographic type with CNVM, $24 \%$ patients were occult type, $6 \%$ of patients were PED, and $2 \%$ patients were disciform scar type. About $22 \%$ of patients were with macular thickness more than $350 \mu, 46 \%$ of patients with between 250 and $350 \mu$, 28\% with 201 and $250 \mu$, 4\% between 150 and $200 \mu$ and there were no patients with macular thickness $<150 \mu$ [Table 2]. Follow-up period ranged from 2 to 16 weeks. All 50 patients completed a 16 weeks follow-up visit. About $52 \%$ cases with classic CNVM showed 1 line improvement in Snellen's chart at the end of 2 months and 56\% of cases showing 2 lines improvement at the end of 4 months. About $2 \%$ patients showed no improvement, and it was found to have CNVM with scar formation [Table 3]. At the end of 2 months $24 \%$ of CNVM showed leakage

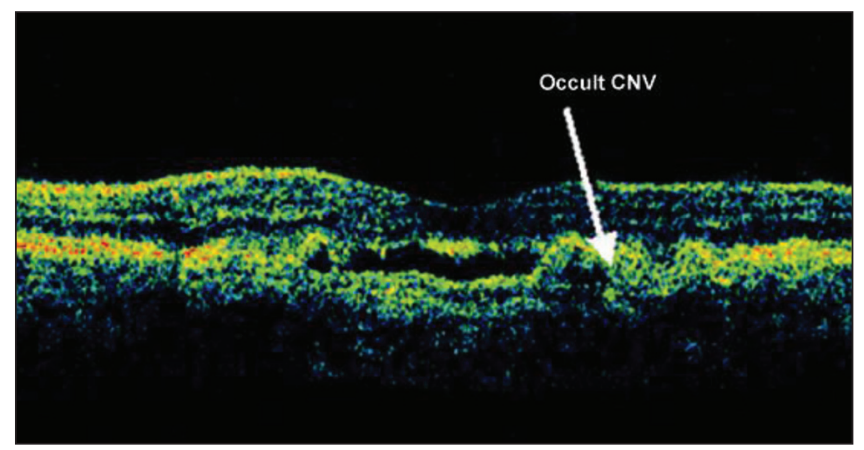

Figure 4: Occult choroidal neovascular membrane in optical coherence tomogram in the fluorescein angiography and 6\% showed leakage at the end of 4 months [Table 4]. The qualitative assessment of the OCT showed marked reduction in subretinal fluid (SRF) and cystic edema 1 month after injection [Figure 5]. The earliest sign of reduction was the disappearance of SRF. About $50 \%$ of classic CNVM and $40 \%$ of occult CNVM showed reduction in macular thickness of $50 \mu$ at the end of 2 months, and $52 \%$ of both CNV types showed reduction of $100 \mu$ at the end of 4 months [Table 5].

Table 1: Systemic risk factors in patients
\begin{tabular}{lc} 
with ARMD $(\boldsymbol{n}=\mathbf{5 0})$ & $\boldsymbol{n}(\%)$ \\
\hline Risk factors & $33(66)$ \\
\hline Hypertension & $22(44)$ \\
Cardiac ailments & $05(10)$ \\
\hline Diabetes
\end{tabular}

ARMD = Age-related macular degeneration

\begin{tabular}{lc} 
Table 2: Macular thickness by optical coherence \\
tomogram $(\boldsymbol{n = 5 0 )}$ \\
\hline Macular thickness $(\mu)$ & $\boldsymbol{n}(\%)$ \\
\hline $100-150$ & - \\
$151-200$ & $2(04)$ \\
$201-250$ & $14(28)$ \\
$251-350$ & $23(46)$ \\
$>350$ & $11(22)$ \\
Total & $50(100)$ \\
\hline
\end{tabular}

\begin{tabular}{|c|c|c|}
\hline $\begin{array}{l}\text { Improvement } \\
\text { of visual acuity }\end{array}$ & At 2 months $n(\%)$ & At 4 months $n(\%)$ \\
\hline No change & $06(12)$ & $04(08)$ \\
\hline 1 line & $26(52)$ & $13(26)$ \\
\hline 2 lines & $14(28)$ & $28(56)$ \\
\hline$>2$ lines & $04(08)$ & $05(10)$ \\
\hline Total & 50 (100) & $50(100)$ \\
\hline
\end{tabular}

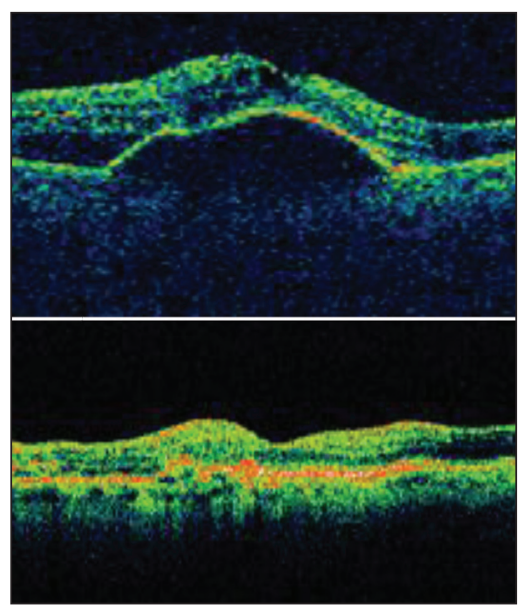

Figure 5: Optical coherence tomogram shows macular thickness before and after injection of bevazimumab 


\begin{tabular}{|c|c|c|}
\hline $\begin{array}{l}\text { Number of cases } \\
\text { with leakage }\end{array}$ & At 2 months $n(\%)$ & At 4 months $n(\%)$ \\
\hline Classic CNVM & $12(24)$ & $03(06)$ \\
\hline Occult CNVM & $04(08)$ & - \\
\hline PED & $03(06)$ & $03(06)$ \\
\hline Disciform scar & $01(02)$ & $01(02)$ \\
\hline
\end{tabular}

\begin{tabular}{|c|c|c|}
\hline $\begin{array}{l}\text { Reduction in macular } \\
\text { thickness }(\mu)\end{array}$ & At 2 months $n(\%)$ & At 4 months $n(\%)$ \\
\hline Up to 50 & $22(44)$ & $10(20)$ \\
\hline $51-100$ & $14(28)$ & $17(34)$ \\
\hline $101-150$ & $04(08)$ & $11(22)$ \\
\hline $151-200$ & - & $05(10)$ \\
\hline$>200$ & - & - \\
\hline No change & $10(20)$ & $07(14)$ \\
\hline Total & $50(100)$ & $50(100)$ \\
\hline
\end{tabular}

\section{DISCUSSION}

The predominant age group was $61-70$ years $(42 \%)$, followed by $71-80$ years $(28 \%)$ and $55-60$ years $(26 \%)$; two patients $(04 \%)$ between the age of 81 and 90 years were affected. This low incidence could be explained by the decreased life span of people in India. The ratio of males to females was 2.3:1. In other studies females out-numbered males. ${ }^{[13]}$ The lower prevalence rate in women in our study could probably be explained by the fact that in developing countries females are usually housewives. They are not aware of their diminished vision as they do not do fine jobs which require good vision. There was bilateral involvement in $94 \%$ of the patients. Among the three patients $(6 \%)$ who presented with unilateral involvement, two patients (4\%) had right eye involvement, and one patient $(2 \%)$ had left eye involvement. This exemplifies the fact that AMD is a bilateral, although asymmetrically affecting both eyes. Sixty four percent of the patients were chronic smokers. According to Stephen Ryan, a definite association exists between AMD and cigarette smoking. This correlation needs elaborate study to explain the pathophysiology of the affection. ${ }^{[15]}$ Though there was association of AMD and hypertension in $66 \%$ in the present study, according to study by Hyman et al. conflicting results have appeared. ${ }^{[16]}$ Most of the cases showed no change in visual acuity in 2 weeks, but about $52 \%$ cases with classic CNVM showed 1 line improvement at the end of 2 months and $56 \%$ of cases showeding 2 lines improvement at the end of 4 months which correlates with Rich, Rosenfeld et al. About $50 \%$ of occult CNV showed more than 2 lines improvement at 4 months which is in par with Geitzenauer et al., Klin Monatsbl Augenheilkd. At the end of 4 weeks, 50\% of both occult and classic types showed leakage and at the end of 4 months no cases of occult CNVM showed leakage which supports the study of Aiesenbrey et al. Graefes one patient of FFA showeds leakage with staining at the end of 4 months because of macular scarring. About $50 \%$ of classic CNV and $40 \%$ of occult $\mathrm{CNV}$ showed reduction in macular thickness of $50 \mu$ at the end of 2 months, and $52 \%$ of both CNV types showed reduction of $100 \mu$ at the end of 4 months, which correlates well with the study of Moschos. About $2 \%$ patients showed no improvement and he it was found to have CNVM with scar formation. This finding correlates with the study in Western countries about $44 \%$ of the patients in our study had nonspecific cardiac ailments. Most of the patients had nonspecific angina. ${ }^{[17]}$ Hence, cardiologist opinion was obtained for all the cardiac patients before giving avastin injection. Five patients $(10 \%)$ were found to have diabetes mellitus. A limitation of this study was small sample size. In further studies, we can compare with two anti VEGF agents and benefits from both and with higher sample size.

\section{CONCLUSION}

The incidence of AMD was high above the age of 60 years. The sex incidence in our study revealed that males were more affected than females (ratio 2.3:1) which did not correlate with the existing studies as many women fail to notice the detoriation of vision and report to the hospital. The Amsler grid chart is one of the useful diagnostic test for follow-up, and patient can monitor their vision with that at home. Hypertension (66\%) and cardiovascular disease (44\%) were found to be the common systemic diseases associated with AMD. Due to the old age patients were finding it difficult for a regular visit to the hospital and they did not come for regular follow-up. In India, ophthalmologists feel that AMD is an uncommon condition. By this study we proved that although its prevalence rate is low in India compared to Western countries, Indians are not immune from developing AMD.

\section{REFERENCES}

1. World Health Organization. Global Initiative for the Elimination of Avoidable Blindness: Action Plan 2006-2011. Geneva: WHO Press; 2007. p. 32-3.

2. Porte C. Pathogenesis and management of age-related macular degeneration. Scott Univ Med J 2012;1:141-53.

3. Schmucker C, Loke YK, Ehlken C, Agostini HT, Hansen LL, Antes G, et al. Intravitreal bevacizumab (Avastin) versus ranibizumab (Lucentis) for the treatment of age-related macular degeneration: A safety review. Br J Ophthalmol 2011;95:308-17.

4. Available from: https://www.nei.nih.gov/health/maculardegen/armd_facts. asp. [Last accessed on 2013 Oct 10].

5. Rosenfeld PJ, Schwartz SD, Blumenkranz MS, Miller JW, Haller JA, Reimann JD, et al. Maximum tolerated dose of a humanized antivascular endothelial growth factor antibody fragment for treating neovascular age-related macular degeneration. Ophthalmology 2005;112:1048-53.

6. Gragoudas ES, Adamis AP, Cunningham ET Jr, Feinsod M, Guyer DR; VEGF Inhibition Study in Ocular Neovascularization Clinical Trial Group. Pegaptanib for neovascular age-related macular degeneration. $\mathrm{N}$ Engl J Med 2004;351:2805-16.

7. Krzystolik MG, Afshari MA, Adamis AP, Gaudreault J, Gragoudas ES, Michaud NA, et al. Prevention of experimental choroidal neovascularization with intravitreal anti-vascular endothelial growth factor antibody fragment. Arch Ophthalmol 2002;120:338-46.

8. Holz FG, Pauleikhoff D, Klein R, Bird AC. Pathogenesis of lesions in late age-related macular disease. Am J Ophthalmol 2004;137:504-10. 
9. Ferrara N. Vascular endothelial growth factor: basic science and clinical progress. Endocr Rev 2004;25:581-611.

10. Michels S, Rosenfeld PJ, Puliafito CA, Marcus EN, Venkatraman AS. Systemic bevacizumab (Avastin) therapy for neovascular age-related macular degeneration twelve-week results of an uncontrolled open-label clinical study. Ophthalmology 2005;112:1035-47.

11. Stephen J. Ryan-Medical Retina. Age Related Macular Degeneration. $5^{\text {th }}$ ed. Saunders: Mosby; 2012. p. 475-7.

12. Age-Related Eye Disease Study Research Group. The Age-Related Eye Disease Study system for classifying age-related macular degeneration from stereoscopic color fundus photographs: The Age-Related Eye Disease Study Report Number 6. Am J Ophthalmol 2001;132: 668-81.

13. Bressler NM, Treatment of Age-Related Macular Degeneration with Photodynamic Therapy (TAP) Study Group. Photodynamic therapy of subfoveal choroidal neovascularization in age-related macular degeneration with verteporfin: Two-year results of 2 randomized clinical trials-tap report 2. Arch Ophthalmol 2001;119:198-207.

14. Rosenfeld PJ, Moshfeghi AA, Puliafito CA. Optical coherence tomography findings after an intravitreal injection of bevacizumab (avastin) for neovascular age-related macular degeneration. Ophthalmic Surg Lasers Imaging 2005;36:331-5.

15. Landers J, Henderson T, Craig J. The prevalence and causes of visual impairment in indigenous Australians within central Australia: The Central Australian Ocular Health Study. Br J Ophthalmol 2010;94:1140-4.

16. Khan JC, Thurlby DA, Shahid H, Clayton DG, Yates JR, Bradley M, et al. Smoking and age related macular degeneration: The number of pack years of cigarette smoking is a major determinant of risk for both geographic atrophy and choroidal neovascularisation. Br J Ophthalmol 2006;90:75-80.

17. Hyman L, Schachat AP, He Q, Leske MC. Hypertension, cardiovascular disease, and age-related macular degeneration. Age-Related Macular Degeneration Risk Factors Study Group. Arch Ophthalmol 2000;118:351-8.

How to cite this article: Raja AM, Janti S, Chendilnathan C, Matheen A. A prospective nonrandomized clinical study on exudative age related macular degeneration. Int J Med Public Health 2014;4:417-21.

Source of Support: Nil, Conflict of Interest: None declared. 